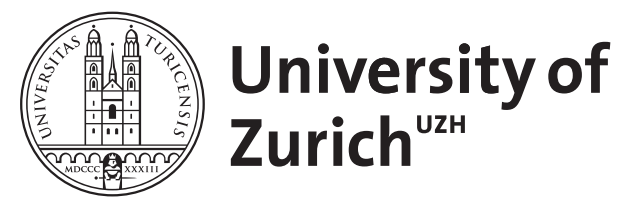

\title{
Controlling ribozyme activity by metal ions
}

Schnabl, J ; Sigel, Roland K O

\begin{abstract}
The observed rates of ribozyme cleavage reactions are strongly dependent on the nature of the metal ion present Metal ions can thereby exhibit a stronger inhibiting or accelerating effect compared to $\mathrm{Mg} 2+$, which is usually considered the natural cofactor. Alkaline, alkaline earth, transition, d(10), and other metal ions are applied either to gain a spectroscopic handle on the metal center, and/or to elucidate the catalytic mechanism. Here we shortly review some of the most recent publications on the influence of different metal ions on catalysis of the hammerhead, hepatitis delta virus, and group II intron ribozymes. Comparison of the observed cleavage rates of hammerhead nbozymes with the metal ion affinities of different ligands reveals that these rates correlate perfectly with the intrinsic phosphate affinities of the metal ions involved.
\end{abstract}

DOI: https://doi.org/10.1016/j.cbpa.2009.11.024

Posted at the Zurich Open Repository and Archive, University of Zurich ZORA URL: https://doi.org/10.5167/uzh-46579

Journal Article

Accepted Version

Originally published at:

Schnabl, J; Sigel, Roland K O (2010). Controlling ribozyme activity by metal ions. Current Opinion in Chemical Biology, 14(2):269-275.

DOI: https://doi.org/10.1016/j.cbpa.2009.11.024 


\title{
Controlling Ribozyme Activity by Metal Ions
}

\author{
Joachim Schnabl, Roland K. O. Sigel*
}

Running title: Metals Controlling Ribozyme Activity

\footnotetext{
* Institute of Inorganic Chemistry University of Zürich

Winterthurerstrasse 190

CH-8057 Zürich, Switzerland

email: roland.sigel@aci.uzh.ch

Fax: ++41-44-635 6802
} 


\section{Abstract}

The observed rates of ribozyme cleavage reactions are strongly dependent on the nature of the metal ion present. Metal ions can thereby exhibit a strong inhibiting or accelerating effect compared to $\mathrm{Mg}^{2+}$, which is usually considered the natural cofactor. Alkaline, alkaline earth, transition, $\mathrm{d}^{10}$, and other metal ions are applied either to gain a spectroscopic handle on the metal center, and/or to elucidate the catalytic mechanism. Here we shortly review some of the most recent publications on the influence of different metal ions on catalysis of the hammerhead, hepatitis delta virus and group II intron ribozymes. Comparison of the observed cleavage rates of hammerhead ribozymes with the metal ion affinities of different ligands reveals that these rates correlate perfectly with the intrinsic phosphate affinities of the metal ions involved.

\section{Introduction}

RNA or DNA in a living cell is always associated with metal ions $\left(\mathrm{M}^{\mathrm{n}+}\right)$ [1]. The intrinsic negative charge of the phosphate sugar backbone needs to be compensated not only to achieve regular duplex formation but even more for complex three-dimensional architectures. Estimates show that a $200 \mathrm{nt}$ long RNA needs to overcome repulsive forces of about $2^{\prime} 100 \mathrm{kJmol}^{-1}$ to fold in the absence of metal ions [2]. The vast majority of $\mathrm{M}^{\mathrm{n}+}$ are diffusely bound to RNA, i.e. via unspecific interactions that can best be described by a non-linear Poisson-Boltzman distribution [3,4]. An estimated $10 \%$ of the negative charge are compensated by specifically bound $\mathrm{M}^{\mathrm{n}+}$, as has been concluded from X-ray structures of larger RNAs [5]. In RNA, a distinct network of inner-sphere (i.e. direct) and outer-sphere (i.e. mediated through water molecules) coordination is built to hold metal ions in place. $\mathrm{A} \mathrm{M}^{\mathrm{n}+}$ binding pocket thereby offers an excess of possible coordination and $\mathrm{H}$ donor/acceptor sites (Figure 1). Outer-sphere binding should thereby not be equated with unspecific binding: If part of a tight hydrogen bonding network, the coordinated water molecules (and thus also the central metal ion) are strongly bound, as is very well known from the spine of hydration of DNA [6].

$\mathrm{K}^{+}$and $\mathrm{Mg}^{2+}$ are most abundant in living cells and thus believed to be the metal ion-cofactors associated with nucleic acids. Originally used as mimics for $\mathrm{Mg}^{2+}$, other divalent metal ions have been applied in uncountable studies to, e.g. elucidate the catalytic mechanism or to get a spectroscopic handle on the metal ion. Thio-rescue [7,8], related NAIM/NAIS experiments (nucleotide analogue interference mapping/suppression) [7,9,10], and EPR measurements are just three examples [11-13]. Such metal ions include alkaline earth ions $\left(\mathrm{Ca}^{2+}, \mathrm{Sr}^{2+}, \mathrm{Ba}^{2+}\right)$, first row transition ions $\left(\mathrm{Mn}^{2+}, \mathrm{Co}^{2+}, \mathrm{Ni}^{2+}\right)$, group $12(\mathrm{IIB})$ ions $\left(\mathrm{Zn}^{2+}, \mathrm{Cd}^{2+}\right)$, main group metal ions $\left(\mathrm{Pb}^{2+}\right)$, 
all lanthanide ions, as well as complexes like $\mathrm{Co}\left(\mathrm{H}_{2} \mathrm{O}\right)_{6}{ }^{3+}$. Changing the metal ion usually strongly affects ribozyme activity. Classically, an inhibiting effect is expected when $\mathrm{Mg}^{2+}$ is partly or fully replaced but also tremendous rate accelerations have been observed. These rate modifications allow to correlate activity with chemico-physical properties of the ions, e.g. ionic radius, $\mathrm{p} K_{\mathrm{a}}$ of coordinated water, or general affinities, and thus help to elucidate the mechanism $[14,15]$. Unfortunately, only rarely clear correlations are found.

In this short review we focus on some of the most recent results on the influence of different metal ions on the cleavage rates of tertiary stabilized hammerhead $(\mathrm{HH})$, hepatitis delta virus (HDV), and group II intron ribozymes. We discuss and compare these data with available results from the literature on smaller nucleic acid systems or derivatives. Interestingly, a clear correlation of $\mathrm{HH}$ ribozyme cleavage rates and the intrinsic affinities of the respective metal ions towards phosphate groups is revealed.

\section{Replacing $\mathrm{Mg}^{2+}$ by monovalent ions}

More than 25 years ago, a two-metal ion mechanism has been proposed for dephosphorylation reactions $[16,17]$ and is now often considered as one of the favored modes of action for ribozymes $[18,19]$. With the discovery that small ribozymes are also active in the presence of monovalent metal ions only, e.g. alkaline ions but also $\mathrm{NH}_{4}{ }^{+}$, this dogma has been strongly opposed for some time. However, given the facts that (i) alkaline ions are also metal ions, (ii) non-physiological molar concentrations have to be applied for folding and activity, (iii) the catalytic activity in the presence of $\mathrm{M}^{+}$ions could in no case rival the one observed with $\mathrm{M}^{2+}$ ions, and (iv) the realization that metal ions need not to be coordinated directly but can exert their crucial influence also from a distance [1], it becomes again increasingly evident, that ribozymes simply are obligate metallo-ribozymes.

It is well known that high $\mathrm{Na}^{+}$concentrations can replace $\mathrm{Mg}^{2+}$ or $\mathrm{Zn}^{2+}$ in the related hydrolysis of ATP [20,21]. 500 times higher concentrations of $\mathrm{M}^{+}$ions are needed in this simple system to compensate for the intrinsic much lower affinity of $\mathrm{M}^{+}$ions compared to $\mathrm{M}^{2+}$ ions. In larger ribozymes, a larger excess of $\mathrm{M}^{+}$is needed. The replacement of one $\mathrm{Mg}^{2+}$ ion by several $\mathrm{Na}^{+}$ions has recently been implicated by a molecular simulation study of the $\mathrm{HH}$ ribozyme, where a large negatively charged binding pocket has been located at the active site [22]. MD simulations in the absence of divalent ions revealed two $\mathrm{Na}^{+}$ions sitting in the catalytic pocket replacing one $\mathrm{Mg}^{2+}$ ion, but not occupying distinct coordination sites [23]. Consistently, the Schistosoma HH ribozyme can globally fold in the presence of $\mathrm{M}^{+}$ions, but $\mathrm{M}^{2+}$ ions are still needed for efficient catalysis [24]. Similar results were obtained for the HDV ribozymes in the presence of molar concentrations 
of $\mathrm{M}^{+}$ions, $\mathrm{Li}^{+}$yielding 30-50 x faster cleavage rates than $\mathrm{Na}^{+}$and $\mathrm{NH}_{4}{ }^{+}$[25]. However, additional presence of $\mathrm{Mg}^{2+}$ further accelerates cleavage by about 100 times [25]. Along the same line, crystallographic studies of the HDV ribozyme have demonstrated that the location of monovalent and divalent ions do not overlap completely [26]. All these results suggest that accumulated $\mathrm{M}^{+}$ions can partly substitute for $\mathrm{Mg}^{2+}$, but they will not reach the equivalent electrostatic or polarizing potential either due to their lower charge density, their lower affinity, or both.

\section{Replacing $\mathrm{Mg}^{2+}$ by $\mathrm{Ca}^{2+}$}

The HDV ribozyme exists in two forms, the genomic and the antigenomic, being encoded one on each of the two viral RNA strands. These two forms exhibit an interesting $\mathrm{Mg}^{2+} / \mathrm{Ca}^{2+}$ switch. Whereas the genomic HDV ribozyme cleaves faster in the presence of $\mathrm{Mg}^{2+}, \mathrm{Ca}^{2+}$ is the better cofactor for the antigenomic form [27]. The nature of the nucleotide 5 to the cleavage site (position $-1)$ ( $U$ in the genomic and $\mathrm{C}$ in the antigenomic HDV ribozyme) is decisive for this specificity, as changing $\mathrm{C} \rightarrow \mathrm{U}$ or $\mathrm{U} \rightarrow \mathrm{C}$, respectively, reverses the $\mathrm{Mg}^{2+} / \mathrm{Ca}^{2+}$ preference [27]. The reason for this switch in $\mathrm{M}^{\mathrm{n}+}$ preference is unknown, but perhaps due to the different hydrogen bonding properties of these two nucleobases the outer-sphere network of the two ions is altered.

The HH ribozyme is one of the best investigated catalytic RNAs. However, despite numerous crystal structures and uncountable biochemical studies, the mechanism of action is still far from being understood $[19,28]$. The HH ribozyme is active in the presence of transition metal ions as well as at high $\mathrm{M}^{+}$concentrations. Since the discovery of the much more active extended (or tertiary stabilized) hammerhead ribozyme [29,30], several studies dealt with the influence of metal ions on catalysis and folding. Out of $\mathrm{Mg}^{2+}, \mathrm{Ca}^{2+}, \mathrm{Sr}^{2+}$, and $\mathrm{Ba}^{2+}, \mathrm{Mg}^{2+}$ works best, the alkaline earth metal ions showing an inverse correlation between $k_{\mathrm{obs}}$ and the $\mathrm{p} K_{\mathrm{a}}$ of the hydrated ions.

Group II introns rank among the largest catalytic RNAs and implicitly require $\mathrm{Mg}^{2+}$ for catalysis [31]. No group II intron is known where the addition of a divalent metal ion other than $\mathrm{Mg}^{2+}$ leads to an increase in activity. The yeast Sc.ai5 $\gamma$ group II intron and its derived ribozyme constructs are among the best investigated large ribozymes [32]. $\mathrm{Ca}^{2+}$ has been shown to be an efficient inhibitor of the first step of splicing of the Sc.ai5 $\gamma$ derived D135 ribozyme: In the presence of $5 \% \mathrm{Ca}^{2+}(95 \%$ $\mathrm{Mg}^{2+}$ ), the catalytic rate $k_{\text {cat }}$ drops by about $50 \%$ and at $20 \% \mathrm{Ca}^{2+}$ no activity is detectable anymore [33]. A replacement of $\mathrm{Mg}^{2+}$ by $\mathrm{Ca}^{2+}$ in the catalytic core can not be excluded to-date. However, recent single molecule Fluorescence Resonance Energy Transfer (smFRET) experiments have provided unprecedented insights into the influence of metal ions on folding of large RNAs [34,35]: (i) The global architecture of these RNAs is severely disturbed upon addition of $\mathrm{Ca}^{2+}$. (ii) $\mathrm{Ca}^{2+}$ 
induces the formation of a second subpopulation that behaves distinctly differently, both in folding pathway and smFRET states. The number of these type 2 molecules thereby increases linearly with $\mathrm{Ca}^{2+}$ concentration. Interestingly, every single molecule is forced into one subpopulation and cannot switch between them. By these experiments, for the first time a functional role for folding heterogeneity could be demonstrated [35]. The observation that not all molecules are evenly affected by $\mathrm{Ca}^{2+}$, hints that $\mathrm{Ca}^{2+}$ coordinates cooperatively. As the total concentration of $\mathrm{Ca}^{2+}$ by far exceeds the one of the single molecules, this means that cooperativity only becomes effective after first binding events have taken place with $\mathrm{Ca}^{2+}$.

\section{Replacing $\mathrm{Mg}^{2+}$ with transition and $\mathrm{d}^{10}$ metal ions}

In the $\mathrm{HH}$ ribozyme all transition metal ions investigated promote faster catalysis than $\mathrm{Mg}^{2+}$, with $\mathrm{Mn}^{2+}$ promoting catalysis about 400 times more than the one reached by $\mathrm{Mg}^{2+}$ [15]. The reason for these large differences in reaction velocity is still unclear. Crystal structures of hammerhead ribozymes in the presence of $\mathrm{Mg}^{2+}, \mathrm{Mn}^{2+}$ and $\mathrm{Cd}^{2+}$ revealed subtle differences in binding (Figure 2) [36,37]: All three ions occupy roughly the same regions but coordinate slightly differently. A closeup of the active site reveals small, but possibly decisive differences of inner-sphere $\left(\mathrm{Mn}^{2+}\right)$ versus outer-sphere coordination $\left(\mathrm{Mg}^{2+}\right)$. Along the same line, recent molecular dynamics simulations of five different hammerhead states have revealed a binding pocket with a high electronegative charge potential that attracts metal ions, but binds them differently in mode and number due to the large enough pocket and excess of possible liganding sites present (Figure 1) [22]. However, different mechanisms might take place depending on the metal ion present: For example, a single-proton transfer was suggested to occur in the presence of $\mathrm{Mg}^{2+}$ or $\mathrm{Mn}^{2+}$, whereas a double-proton transfer might take place with $\mathrm{Cd}^{2+}$ in the case of the RzB HH ribozyme [15]. As an acid, either a solvated $\mathrm{Mg}^{2+}$ ion or a guanine-N1H, both with a perturbed $\mathrm{p} K_{\mathrm{a}}$ value have been suggested. The origin of perturbed $\mathrm{p} K_{\mathrm{a}} \mathrm{s}$ in complex RNAs is largely unknown. From nucleobase studies, coordinating $\mathrm{M}^{\mathrm{n}+}$ are well known to shift $\mathrm{p} K_{\mathrm{a}} \mathrm{s}$ into the physiological range as was recently reviewed (Figure 3) [38]. Indeed, in the VS ribozyme it was recently reported that metal ions control a nucleobase $\mathrm{p} K_{\mathrm{a}}$ [39]. The polarizing effect of $\mathrm{Mg}^{2+}$ is expected to be similar to that of a kinetically stable $\mathrm{M}^{\mathrm{n}+}$ like $\mathrm{Pt}^{2+}$, if $\mathrm{Mg}^{2+}$ is held tightly in place by further coordination. The largest effect on $\mathrm{p} K_{\mathrm{a}}$ is actually enforced by protons, e.g. guanine-N7 protonation shifts the $\mathrm{p} K_{\mathrm{a}}$ of $\mathrm{N} 1 \mathrm{H}$ to 7.22 (Figure 3) [40].

Recently, the effect of $\mathrm{Mg}^{2+}, \mathrm{Ca}^{2+}, \mathrm{Sr}^{2+}, \mathrm{Mn}^{2+}, \mathrm{Co}^{2+}, \mathrm{Zn}^{2+}, \mathrm{Cd}^{2+}, \mathrm{Na}^{+}$, and $\mathrm{NH}_{4}^{+}$was investigated not only on catalysis but also on folding of the Schistosoma mansonii HH by FRET [24]. All $\mathrm{M}^{\mathrm{n}+}$ are capable of globally folding the HH ribozyme, but 10'000 fold differences in cleavage rates are 
observed, $\mathrm{Mn}^{2+}$ again being the best cofactor [24]. When folded in $2 \mathrm{M} \mathrm{Na}^{+}$, still a $>4600$ fold activation of cleavage can be observed for $\mathrm{Mn}^{2+}$ compared to $\mathrm{Mg}^{2+}$. Taken together, this is strong indication for a direct involvement of the metal ion in optimal cleavage activity.

\section{The change in cleavage rate follows the phosphate affinity of the applied metal ion}

Correlations of the observed catalytic rates $k_{\mathrm{obs}}$ with ionic radii, $\mathrm{p} K_{\mathrm{a}}$ values of the hydrated metal ion complexes, the Irving-Williams series (Figure 4A) or others have been attempted in the past. No clear correlation was observed for all studied metal ions, again suggesting that different mechanisms might occur. In this regard, single and double proton transfer mechanisms involving either hydrated metal ions or ionized nucleobases are being considered [19,28,40,41]. Considering the intrinsic coordination chemical properties of the metal ions involved, it is actually very unlikely that any straight trends are observed: (i) Along the Irving-Williams series not only the affinity of metal ion-ligand interactions increases, but also the preference for oxygen ligands changes to a clear preference for nitrogen sites. Both types of liganding sites are abundant in metal ion binding pockets within nucleic acid structures (Figures 1 and 3). (ii) At the same time, the preference for inner-sphere coordination often increases from left to right along the same series of ions (which is not true for phosphate ligands). (iii) The Irving-Williams series is not strictly followed for phosphate ligands, which are the most important coordination sites for metal ions in nucleic acids (Figure 4) $[42,43]$. Most importantly, the phosphate affinity decreases from $\mathrm{Mn}^{2+}$ to $\mathrm{Ni}^{2+}$ (most likely due to outer-sphere binding).

Indeed, when plotting the $k_{\mathrm{obs}}$ values of RzB HH cleavage $[15,24]$ versus the $\mathrm{M}^{\mathrm{n}+}$ affinities towards a phosphate monoester, a surprisingly good correlation is observed (Figure 4B). The $k_{\mathrm{obs}}$ values observed with the alkaline earth $\mathrm{M}^{2+}$ and $\mathrm{Mn}^{2+}$ fit well to the Irving-Williams series as well as to the phosphate affinities. The additionally investigated transition and $\mathrm{d}^{10} \mathrm{M}^{2+}$ do clearly not follow anymore the Irving-Williams trend but almost perfectly the one of the phosphate affinities with $\mathrm{Mn}^{2+}$ exhibiting both the highest $k_{\mathrm{obs}}$ and affinities (Figure 4). As the nucleotide affinities are strongly dominated by the phosphate- $\mathrm{M}^{\mathrm{n}+}$ interaction [5,42], this result shows that the strength of the phosphate coordination dominates the effect of metal ions on catalysis in at least the $\mathrm{HH}$ ribozyme.

\section{Conclusions}

The nature of divalent metal ions obviously is the determining factor how RNAs fold and what mechanism is employed. How this is achieved is still lying mainly in the dark - especially 
concerning the picture on the atomic level. The above summarized recent results on the effect of varying metal ions on ribozyme activity now trigger several considerations:

(i) There is increasing evidence that ribozymes use different mechanisms depending on the outside conditions, e.g. the kind and concentration of metal ions employed. As a consequence this means that the employment of mimics, e.g. $\mathrm{Cd}^{2+}$ instead of $\mathrm{Mg}^{2+}$, might not reflect the "real" catalytic mechanism but rather a minor or very different pathway. Such concerns have increasingly been raised in the past years, e.g. for HH ribozymes [10]. The transfer of such results to the wild-type system should thus always be performed with care.

(ii) Complex RNA structures are surprisingly selective for a given metal ion, i.e. they recognize it with high specificity and selectivity. One could argue that such specific binding pockets exist just by chance or based on pure statistics. On the other hand Nature is very efficient and has had millions of years to optimize its processes. In evolutionary terms, one can imagine that there is hardly any chance that the highly effective binding of various metal ions and their considerable effects on ribozyme activity is without any purpose. This is even more so, as such effects are not restricted to only one specific ribozyme, but seem to be a more widespread phenomenon. As a consequence, a possible regulation of ribozyme activity by metal ions is an intriguing possibility [33]. $\mathrm{Mg}^{2+}$ and $\mathrm{Ca}^{2+}$ occur solvated in the cell plasma, but others like $\mathrm{Mn}^{2+}$ could be specifically delivered by proteins.

(iii) Metal ions other than $\mathrm{Mg}^{2+}$ often bind with considerably higher affinity than $\mathrm{Mg}^{2+}$ itself. In the case of transition or $\mathrm{d}^{10}$ elements, this is no surprise due to their relative positioning in the IrvingWilliams series. This is not true for $\mathrm{Ca}^{2+}$ as for example its affinity to the RNA building block $\mathrm{AMP}^{2-}$ is $25 \%$ lower than that of $\mathrm{Mg}^{2+}[5,44]$. Nevertheless, even at a ten-fold excess of $\mathrm{Mg}^{2+}, \mathrm{Ca}^{2+}$ can completely inhibit splicing of a group II intron construct. Consequently, at least one $\mathrm{Ca}^{2+}$ specific binding pocket must exist, where the affinity is more than $1^{\prime} 000 \mathrm{x}$ higher than for $\mathrm{Mg}^{2+}$ (to reach $99 \%$ inhibition). Such an increase in affinity only requires an additional binding energy of 17 $\mathrm{kJmol}^{-1}$, i.e. corresponding to one additional hydrogen bond of a coordinated water molecule. Hence, together with the increased ionic radius (66 vs. 99 pm) and higher maximal coordination number (6 vs. 8), such specific binding pockets can be easily envisaged.

(iv) The observed folding heterogeneity of a group II intron ribozyme in the presence of $\mathrm{Ca}^{2+}$ by smFRET could also be true for other ribozymes when being accelerated with different metal ions. The small FRET differences observed with the group II intron make it impossible to see the same in bulk experiments. Consequently future smFRET studies might reveal highly interesting and unprecedented aspects of how different metal ions influence and control folding and activity of 
ribozymes.

(v) Evaluation of the available data in the recent literature shows that in the $\mathrm{HH}$ ribozyme the rate is majorily governed by the metal ion affinity to the phosphate group(s) (Figure 4B) following a clear trend. It will be interesting to see if this is also true for other catalytic RNAs, if not for the more complex large ones, than at least for the small ribozymes.

\section{Conflicts of interest}

The authors declare no conflict of interest

\section{Acknowledgements}

The authors apologize to all those colleagues whose work could not be cited here due to space limitations. We are very grateful to the Swiss National Science Foundation (200021-124834/1 and 200021-117999 to RKOS), the Swiss State Secretariat of Education and Research within the COST Action D39, and the University of Zürich for supporting our work on the interaction of metal ions and metal ion complexes with ribozymes, riboswitches and DNA.

\section{References and recommended reading}

Papers of particular interest, published within the past 2-3 years are highlighted as:

- of special interest

$\bullet \bullet$ of outstanding interest

1. Sigel RKO, Pyle AM: Alternative roles for metal ions in enzyme catalysis and the implication for ribozyme chemistry. Chem Rev 2007, 107:97-113.

- A review that transfers the knowledge on metalloproteins to ribozymes showing that metal ions can exert their influence on catalysis also from distance.

2. Bai Y, Das R, Millett IS, Herschlag D, Doniach S: Probing counterion modulated repulsion and attraction between nucleic acid duplexes in solution. P Natl Acad Sci USA 2005, 102:1035-1040.

3. Chu VB, Bai Y, Lipfert J, Herschlag D, Doniach S: A repulsive field: Advances in the electrostatics of the ion atmosphere. Curr Op Chem Biol 2008, 12:619-625.

4. Draper DE: RNA folding: Thermodynamic and molecular descriptions of the roles of ions. Biophys $J$ 2008, 95:5489-5495.

5. Freisinger E, Sigel RKO: From nucleotides to ribozymes - a comparison of their metal ion binding properties. Coord Chem Rev 2007, 251:1834-1851.

6. Freisinger E, Fernandes A, Grollman AP, Kisker C: Crystallographic characterization of an exocyclic DNA adduct: 3,N4-etheno-2'-deoxycytidine in the dodecamer 5'- 
CGCGAATTECGCG-3' . J Mol Biol 2003, 329:685-697.

7. Gordon PM, Fong R, Piccirilli JA: A second divalent metal ion in the group II intron reaction center. Chem Biol 2007, 14:607-612.

- Identification of a second metal ion required for nucleophile activation in the step of exon ligation. Comparison with similar experiments using group I introns suggests a two-metal ion mechanism as a paradigm for large ribozymes.

8. Hougland JL, Kravchuk AV, Herschlag D, Piccirilli JA: Functional identification of catalytic metal ion binding sites within RNA. Plos Biology 2005, 3:1536-1548.

9. Boudvillain M, Pyle AM: Defining functional groups, core structural features and interdomain tertiary contacts essential for group II intron self-splicing: a NAIM analysis. EMBO J 1998, 17:7091-7104.

10. Osborne EM, Ward WL, Ruehle MZ, DeRose VJ: The identity of the nucleophile substitution may influence metal interactions with the cleavage site of the minimal hammerhead ribozyme. Biochemistry 2009, 48:10654-10664.

- A study indicating that results from nucleotide modifications have to be interpreted with care as the change in local environment might alter the general mechanism.

11. Kisseleva N, Khvorova A, Westhof E, Schiemann O, Wolfson AD: The different role of high-affinity and low-affinity metal ions in cleavage by a tertiary stabilized cis hammerhead ribozyme from tobacco ringspot virus. Oligonucleotides 2008, 18:101-110.

12. Kisseleva N, Kraut S, Jaschke A, Schiemann O: Characterizing multiple metal ion binding sites within a ribozyme by cadmium-induced EPR silencing. HFSP J 2007, 1:127-136.

13. Hoogstraten CG, Grant CV, Horton TE, DeRose VJ, Britt RD: Structural analysis of metal ion ligation to nucleotides and nucleic acids using pulsed EPR spectroscopy. $J$ Am Chem Soc 2002, 124:834-842.

14. Dahm SC, Uhlenbeck OC: Role of divalent metal ions in the hammerhead RNA cleavage reaction. Biochemistry 1991, 30:9464-9469.

15. Roychowdhury-Saha M, Burke DH: Extraordinary rates of transition metal ionmediated ribozyme catalysis. RNA 2006, 12:1846-1852.

16. Sigel H, Hofstetter F, Martin RB, Milburn RM, Scheller-Krattiger V, Scheller KH:

Hydrolysis of nucleoside phosphates. 8. General considerations on transphosphorylations - Mechanism of the metal ion-facilitated dephosphorylation of nucleoside 5'-triphosphates, including promotion of ATP dephosphorylation by addition of adenosine 5'-monophosphate. J Am Chem Soc 1984, 106:7935-7946.

17. Sigel H: Mechanistic aspects of the metal ion promoted hydrolysis of nucleoside 5'triphosphates (NTPs). Coord Chem Rev 1990, 100:453-539.

18. Toor N, Keating KS, Taylor SD, Pyle AM: Crystal structure of a self-spliced group II intron. Science 2008, 320:77-82.

- $\quad$ First crystal structure of a complete group II intron ribozyme. Two metal ions are found in the catalytic core being indicative of a two-metal ion mechanism. 
19. Fedor MJ: Comparative enzymology and structural biology of RNA self-cleavage. Ann Rev Biophys 2009, 38:271-299.

20. Sigel H, Tribolet R: Hydrolysis of nucleoside phosphates. 11. Synergism between different metal-ions in the dephosphorylation of adenosine 5 '-triphosphate (ATP) in mixed metal-ion ATP systems, and influence of a decreasing solvent polarity (dioxanewater mixtures) on the dephosphorylation rate - effects of $\mathrm{Mg}^{2+}, \mathrm{Na}^{+}$, and $\mathrm{NH}_{4}{ }^{+}$ions. $J$ Inorg Biochem 1990, 40:163-179.

21. Sigel H: Have ATP and related purine nucleotides played a role in early evolution? ATP, its own 'enzyme' in metal ion facilitated hydrolysis. Inorg Chim Acta 1992, 198200:1-11.

22. Lee T-S, Giambasu GM, Sosa CP, Martick M, Scott WG, York DM: Threshold occupancy and specific cation binding modes in the hammerhead ribozyme active site are required for active conformation. J Mol Biol 2009, 388:195-206.

23. Krasovska MV, Sefcikova J, Reblova K, Schneider B, Walter NG, Sponer J: Cations and hydration in catalytic RNA: Molecular dynamics of the hepatitis delta virus ribozyme. Biophys J 2006, 91:626-638.

24. Boots JL, Canny MD, Azimi E, Pardi A: Metal ion specificities for folding and cleavage activity in the Schistosoma hammerhead ribozyme. RNA 2008, 14:2212-2222.

- $\quad$ Detailed FRET investigation of the effect of different metal ions on the folding and catalytic cleavage reaction of the tertiary stabilized Schistosoma hammerhead ribozyme, sperating the effect on folding and cleavage.

25. Perrotta AT, Been MD: HDV ribozyme activity in monovalent cations. Biochemistry 2006, 45:11357-11365.

26. Ke A, Ding F, Batchelor JD, Doudna JA: Structural roles of monovalent cations in the HDV ribozyme. Structure 2007, 15:281-287.

27. Perrotta AT, Been MD: A single nucleotide linked to a switch in metal ion reactivity preference in the HDV ribozymes. Biochemistry 2007, 46:5124-5130.

- $\mathrm{A} \mathrm{C} / \mathrm{U}$ or $\mathrm{U} / \mathrm{C}$ switch at the corresponding position in the genomic and antigenomic HDV ribozyme changes the preference for $\mathrm{Mg}^{2+}$ and $\mathrm{Ca}^{2+}$ in catalysis.

28. Martick M, Lee T-S, York DM, Scott WG: Solvent structure and hammerhead ribozyme catalysis. Chem Biol 2008, 15:332-342.

29. Khvorova A, Lescoute A, Westhof E, Jayasena SD: Sequence elements outside the hammerhead ribozyme catalytic core enable intracellular activity. Nature Struct Biol 2003, 10:708-712.

30. De la Pena M, Gago S, Flores R: Peripheral regions of natural hammerhead ribozymes greatly increase their self-cleavage activity. EMBO J 2003, 22:5561-5570.

31. Sigel RKO: Group II intron ribozymes and metal ions - a delicate relationship. Eur J Inorg Chem 2005, 12:2281-2292. 
32. Fedorova O, Zingler N: Group II introns: structure, folding and splicing mechanism. Biol Chem 2007, 388:665-678.

33. Erat MC, Sigel RKO: Divalent metal ions tune the self-splicing reaction of the yeast mitochondrial group II intron Sc.ai5 $\gamma$. J Biol Inorg Chem 2008, 13:1025-1036.

- A surprisingly strong inhibiting effect of minimal amounts of $\mathrm{Ca}^{2+}$ is described for the first step of splicing of a group II intron, indicating specific $\mathrm{Ca}^{2+}$ binding sites within the active structure.

34. Steiner M, Karunatilaka KS, Sigel RKO, Rueda D: Single molecule studies of group II intron ribozymes. Proc Natl Acad Sci USA 2008, 105:13853-13858.

35. Steiner M, Rueda D, Sigel RKO: Impact of $\mathbf{C a}^{2+}$ on single molecule folding of a group II intron ribozyme. Angew Chem Int Ed 2009, available online:doi:

10.1002/anie.200903809.

- $\quad$ Single molecule FRET study on a group II intron ribozyme establishing for the first time a functional role of folding heterogeneity: In the presence of $\mathrm{Ca}^{2+}$, the intron folds into two distinct subpopulations that do not interchange.

36. Scott WG, Murray JB, Arnold JRP, Stoddard BL, Klug A: Capturing the structure of a catalytic RNA intermediate: The hammerhead ribozyme. Science 1996, 274:2065-2069.

37. Murray JB, Szoke H, Szoke A, Scott WG: Capture and visualization of a catalytic RNA enzyme-product complex using crystal lattice trapping and $\mathrm{X}$-ray holographic reconstruction. Mol Cell 2000, 5:279-287.

38. Lippert B: Ligand-p $K_{\mathbf{a}}$ shifts through metals: Potential relevance to ribozyme chemistry. Chem Biodivers 2008, 5:1455-1474.

- A review summarizing the knowledge on metal ion-induced $\mathrm{p} K_{\mathrm{a}}$ shifts in modelsystems and transfering it to ribozymes.

39. Smith MD, Mehdizadeh R, Olive JE, Collins RA: The ionic environment determines ribozyme cleavage rate by modulation of nucleobase $\mathbf{p} \boldsymbol{K}_{\mathbf{a}} . R N A 2008, \mathbf{1 4}: 1942-1949$.

- $\quad$ Correlation of the shift in nucleobase $\mathrm{p} K_{\mathrm{a}}$ into the physiological $\mathrm{pH}$ range with the electrostatic effects of different metal ions in the VS ribozyme.

40. Knobloch B, Sigel RKO, Lippert B, Sigel H: Two metal ions coordinated to a purine residue tolerate each other well! Angew Chem, Int Ed 2004, 43:3793-3795.

41. Cerrone-Szakal AL, Siegfried NA, Bevilacqua PC: Mechanistic characterization of the HDV genomic ribozyme: Solvent isotope effects and proton inventories in the absence of divalent metal ions support $\mathbf{C 7 5}$ as the general acid. $J$ Am Chem Soc 2008, 130:1450414520.

- A thorough and detailed study on proton transfers taking part the catalytic steps of the HDV genomic ribozyme.

42. Sigel H, Griesser R: Nucleoside 5'-triphosphates: Self-association, acid-base, and metal ion-binding properties in solution. Chem Soc Rev 2005, 34:875-900.

43. Sigel RKO, Sigel H: Complex formation of Nickel(II) and related metal ions with sugar residues, nucleobases, phosphates, nucleotides, and nucleic acids. Met Ions Life Sci 2007, 2:109-180. 
44. Sigel H, Song B: Solution structures of nucleotide-metal ion complexes. Isomeric equilibria. Met Ions Biol Syst 1996, 32:135-206.

45. Erat MC, Sigel RKO: Determination of the intrinsic affinities of multiple site-specific $\mathrm{Mg}^{2+}$ ions coordinated to domain 6 of a group II intron ribozyme. Inorg Chem 2007, 46:11224-11234.

46. Erat MC, Zerbe O, Fox T, Sigel RKO: Solution structure of the domain 6 from a selfsplicing group II intron ribozyme: $\mathrm{A} \mathrm{Mg}^{2+}$ binding site is located close to the stacked branch adenosine. ChemBioChem 2007, 8:306-314.

47. Chi Y-I, Martick M, Lares M, Kim R, Scott WG, Kim S-H: Capturing hammerhead ribozyme structures in action by modulating general base catalysis. PLoS Biology 2008, 6:e234-e234.

48. Sigel H, McCormick DB: On the discriminating behavior of metal ions and ligands with regard to their biological significance. Accounts Chem Res 1970, 3:201-208.

49. Knobloch B, Linert W, Sigel H: Metal ion-binding properties of (N3)-deprotonated uridine, thymidine, and related pyrimidine nucleosides in aqueous solution. Proc Natl Acad Sci USA 2005, 102:7459-7464.

50. Mucha A, Knobloch B, Jeżowska-Bojczuk M, Kozłowski H, Sigel RKO: Acid-base properties of ribose versus 2'-deoxyribose nucleotides. Chem Eur J 2008, 14:6663-6671. 


\section{Figure Legends}

Figure 1. Metal ion binding pocket in the major groove of the branch site in domain 6 of the Sc.ai5 $\gamma$ ribozyme $[45,46]$. A multitude of possible coordination sites for a metal ion (oxygens in red, nitrogens in blue) as well as one $\mathrm{H}$-bond donor $\left(\mathrm{NH}_{2}\right.$ in green) are observed. It is highly plausible that depending on the size and coordinating properties of a given metal ion, a specific network of hydrogen bonds and coordination patterns for each distinct metal ion can be achieved in such a pocket. This Figure was prepared with MOLMOL (www.mol.biol.ethz.ch/groups/wuthrich_group/software) using PDB ID 2AHT [46].

Figure 2. (A) Overlay of crystal structures of $\mathrm{HH}$ ribozymes in the presence of $\mathrm{Mg}^{2+}$ (green spheres, PDB ID 301D) [36], $\mathrm{Mn}^{2+}$ (blue spheres, PDB ID 300D) [36], and $\mathrm{Cd}^{2+}$ (yellow spheres, PDB ID 488D) [37]. $\mathrm{Mg}^{2+}$ and $\mathrm{Mn}^{2+}$ occupy corresponding regions, but coordinate differently, whereas $\mathrm{Cd}^{2+}$ preferes other binding sites. (B) Close-up of the active site: $\mathrm{The}^{\mathrm{Mn}^{2+}}$ is bound innersphere both to the pro- $R_{\mathrm{P}}$ phosphate oxygen at nucleotide A9 and N7 of G10.1 (PDB ID 2OEU) [28]. $\mathrm{Mg}^{2+}$ also coordinates inner-sphere to the same phosphate oxygen but outer-sphere to the respective N7 position as indicated by the large distance of $4.5 \AA$ (PDB ID 2QUW) [47]. The panels were prepared with MOLMOL (www.mol.biol.ethz.ch/groups/wuthrich_group/software).

Figure 3. (A) Metal ion coordinating atoms and $\mathrm{p} K_{\mathrm{a}}$ values of RNA nucleobases. The $\mathrm{p} K_{\mathrm{a}}$ values are taken from references [49], [42] and [50]. In the case of gua and ura the effect of a singlecharged phosphate group was additionally taken into account. (B) The effect of N7 substituents on the $\mathrm{p} K_{\mathrm{a}}$ of the guanine $\mathrm{N} 1 \mathrm{H}$ position. The $\Delta \mathrm{p} K_{\mathrm{a}}$ values are taken from reference [40] to calculate the expected values $\mathrm{p} K_{\mathrm{a}, \text { ex }}$ values based on $\mathrm{p} K_{\mathrm{a}}=9.36$ as given in (A).

Figure 4. Comparison of the observed rates of $\mathrm{HH}$ cleavage $k_{\mathrm{obs}}$ in the presence of various divalent metal ions with the affinities of these $\mathrm{M}^{2+}$ towards different ligands. (A) Classical Irving-Williams series as observed for metal ion binding to acetate $(\Delta)$, imidazole, and $(\square) \mathrm{NH}_{3}(\diamond)[48]$. No overall correleation with the $k_{\mathrm{obs}}$ values from RzB HH ( $\mathbf{0}$ ) [15] and the Schistosoma HH ( $\Delta$ ) [24] cleavage is observed. (B) The observed RzB HH ( $\mathbf{0}$ ) [15] and Schistosoma HH ( $\mathbf{\Delta}$ ) [24] cleavage rates $k_{\mathrm{obs}}$ correlate nicely with the affinities $[5,42]$ of the respective $\mathrm{M}^{2+}$ towards a phosphate monoester with $\mathrm{p} K_{\mathrm{H}(\mathrm{R}-\mathrm{MP})}^{\mathrm{H}}=6.20$. This strongly suggests that the strength of the phosphate coordination dominates the metal ion effect in the HH ribozyme. Further properties like the $\mathrm{p} K_{\mathrm{a}}$ of coordinated water molecules then determine, e.g. the acid-base profile of catalysis. 


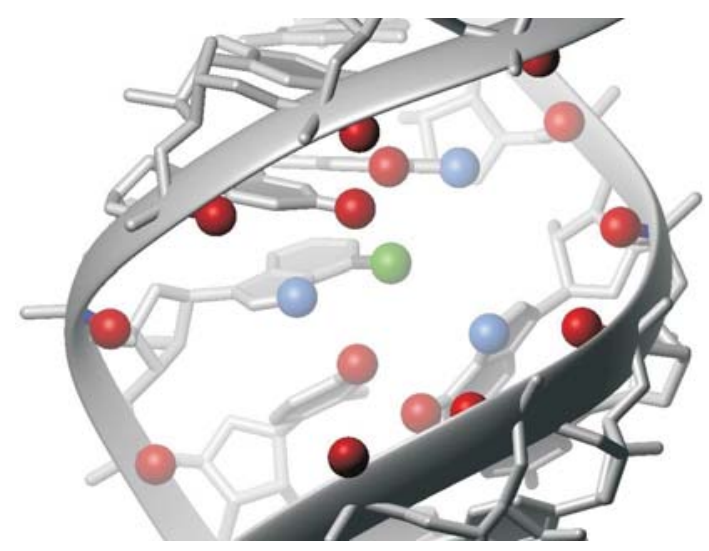

Figure 1 


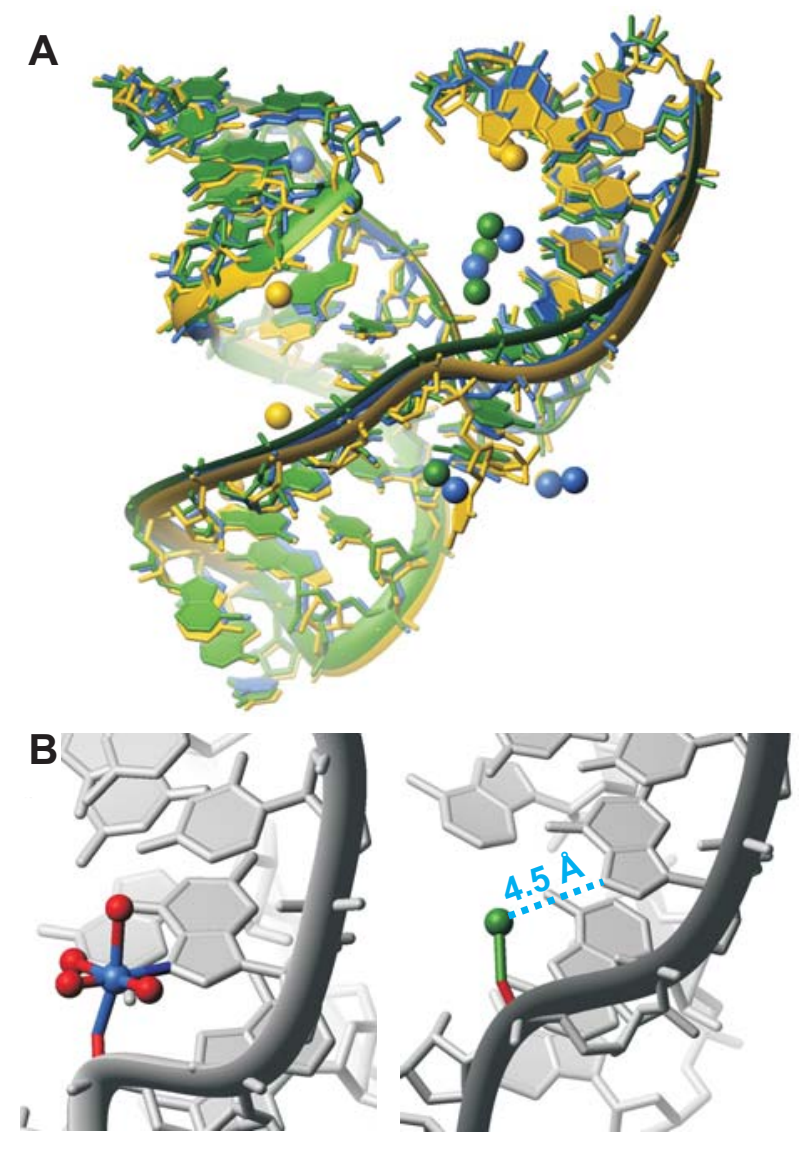

Figure 2 
A

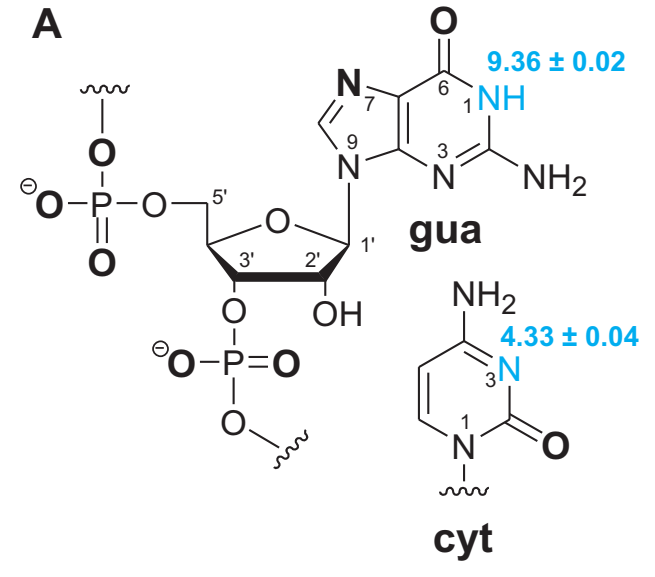

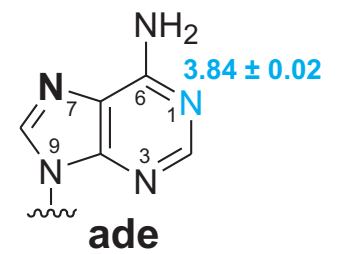

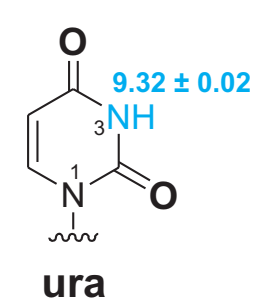

B

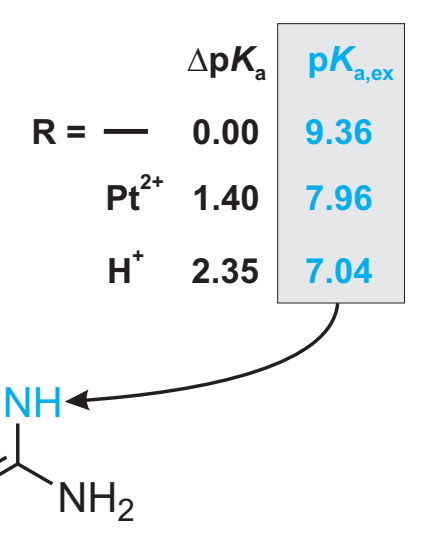

Figure 3 

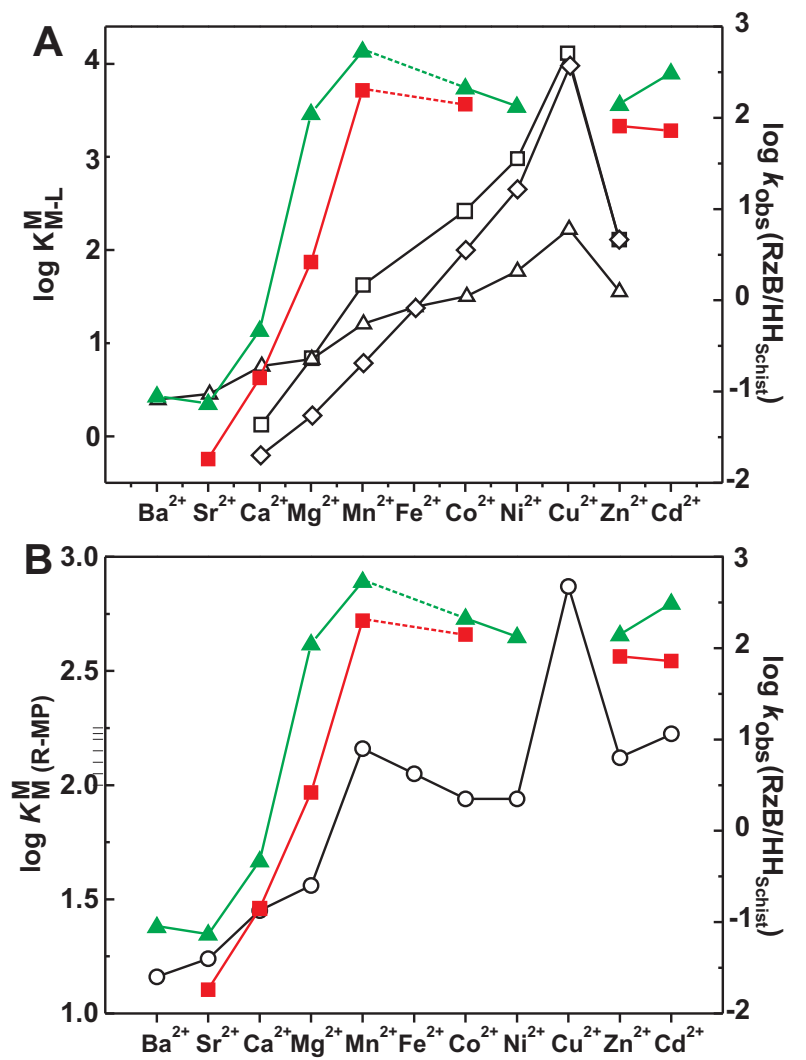

Figure 4 